\title{
Kits para aerossol em um serviço de saúde: uma análise microbiológica após reprocessamento
}

\author{
AEROSOL KITS IN A HEALTH SERVICE: A POST-PROCESSING MICROBIOLOGIC ANALYSIS \\ KITS PARAAEROSOL EN UN SERVICIO DE SALUD: \\ UN ANÁLISIS MICROBIOLÓGICO POST PROCESAMIENTO
}

\author{
Patrícia Staciarini Anders ${ }^{1}$, Anaclara Ferreira Veiga Tipple ${ }^{2}$, Fabiana Cristina Pimenta ${ }^{3}$
}

\section{RESUMO}

Kits para aerossol são artigos utilizados na terapêutica de afecções do trato respiratório e requerem no mínimo desinfecção de nível intermediário para reuso. Os objetivos deste estudo foram verificar uma possível contaminação microbiana em kits para aerossol pós-reprocessamento e identificar os microrganismos isolados. Estudo transversal, experimental realizado na unidade pediátrica de um hospital em Goiânia-GO. Coletaram-se amostras de três segmentos (máscara, copo, interior da extensão) de 15 kits previamente desinfetados, que foram semeadas em diferentes meios de culturas e os microrganismos isolados foram identificados por provas bioquímicas. Dos 15 kits analisados, 13 copos, nove extensões e 13 máscaras estavam contaminados. Isolou-se no total 101 UFC, 39 provindos dos copos, 20 das extensões e 42 das máscaras. Dentre os patógenos isolados destaca-se: Staphylococcus coagulase positivo, Staphylococcus coagulase negativo, Bastonetes Gram negativo fermentadores, Bastonetes Gram negativo não fermentadores, micrococose leveduras. A detecção microbiana indica prováveis falhas no reprocessamento desses artigos.

\section{DESCRITORES}

Inaladores dosimetrados.

Descontaminação.

Infecção hospitalar.

\begin{abstract}
Aerosol kits are used in treatments of respiratory illnesses and require at least an intermediate level of disinfection for their reuse. The objectives of the study were to verify possible contamination of kits after they were processed as well as to identify the microorganisms that were isolated in them. This transversal experimental study was conducted in the pediatric unit of a hospital in Goiânia, State of Goiás. Samples were collected from three different parts (masks, cups and hoses) of 15 previously disinfected kits and placed in different culture media, and the microorganisms that were isolated were identified through biochemical tests. Of the kits that were analyzed, 13 cups, 9 hoses and 13 masks were found to be contaminated. A total of 101 CFU were isolated - 39 from the cups, 20 from the hoses, and 42 the masks. Among the pathogens found were coagulasepositive Staphylococci, coagulase-negative Staphylococci, Gram negative fermenter rods, Gram negative nonfermenter rods, micrococcus and yeast. Microbial presence indicates probable inefficiencies in processing these items.
\end{abstract}

\section{KEY WORDS}

Metered dose inhalers.

Decontamination.

Cross infection.

\section{RESUMEN}

Kits para aerosol son artículos utilizados en la terapéutica de afecciones del tracto respiratorio y requieren en lo mínimo desinfección a nivel intermediario para volver a ser usado. Los objetivos de este estudio fueron verificar una posible contaminación microbiológica en kits para aerosol postreprocesamiento e identificar los microorganismos aislados. Se trata de un estudio transversal, experimental realizado en la unidad pediátrica de un hospital en Goiânia-GO. Se recolectaron muestras de tres segmentos (máscara, vaso, interior de la extensión) de 15 kits previamente desinfectados, que fueron sembradas en diferentes medios de cultivo y los microorganismos aislados fueron identificados por pruebas bioquímicas. De los 15 kits analizados, 13 vasos, nueve extensiones y 13 máscaras estaban contaminados. Se aisló un total de 101 UFC, 39 provenientes de los vasos, 20 de las extensiones y 42 de las máscaras. Entre los patógenos aislados se destacan: Staphylococcus coagulase positivo, Staphylococcus coagulase negativo, Bastones Gram negativo fermentadores, Bastones Gram negativo no fermentadores, micrococos y levaduras. La detección microbiológica indica probables fallas en el reprocesamiento de esos artículos.

\section{DESCRIPTORES}

Inhaladores de dosis medida.

Descontaminación.

Infección hospitalaria.

\footnotetext{
${ }^{1}$ Enfermeira, Mestre em Medicina Tropical (área de Concentração: Microbiologia) pelo Instituto de Patologia Tropical e Saúde Pública/ UFG. Goiânia,Goiás, Brasil. pstaciarini@yahoo.com.br ${ }^{2}$ Enfermeira, Doutora em Enfermagem pela Escola de Enfermagem de Ribeirão Preto/ USP, Profa. Adjunta da Faculdade de Enfermagem/ UFG. Goiânia,Goiás, Brasil. ${ }^{3}$ Farmacêutica, Doutora em Ciências (Microbiologia) pela Universidade Federal do Rio de Janeiro, Professora Adjunta do Instituto de Patologia Tropical e Saúde Pública / UFG. Goiânia,Goiás, Brasil.
} 


\section{INTRODUÇÃO}

A importância do reprocessamento de artigos na prevenção de infecção nosocomial é evidente, pois artigos inadequadamente limpos, desinfetados ou esterilizados tornam-se fonte de contaminação e risco de aquisição de microrganismos, tanto para o paciente como para o profissional| $^{(1-2)}$.

Para a escolha do tipo de reprocessamento que um artigo será submetido avalia-se primariamente o risco potencial da ocorrência de infecção, associado à sua utilização(2-3). Por entrarem em contato com membranas mucosas, os Kits para aerossol são considerados artigos semicríticos. As mucosas e pele intactas impedem a penetração de alguns microrganismos e esporos bacterianos, mas são suscetíveis a outros, como vírus e bactérias invasivas. Esses itens requerem no mínimo desinfecção de nível intermediário, obtido por desinfetantes químicos ou métodos físicos, como equipamentostermo-desinfetadores ${ }^{(4-6)}$.

Os Kits para aerossol são utilizados geralmente na terapêutica de afecções do trato respiratório para alívio de processos inflamatórios, congestivos e obstrutivos. As micropartículas de água, associadas ou não a medicamentos, são introduzidas nas vias aéreas por inalação com auxílio de oxigênio ou ar comprimido. Quanto menores as partículas, maior a profundidade de penetração. Os nebulizadores mecânicos simples produzem partículas com dimensões de 0,5 a 5 micras e os nebulizadores ultra-sônicos de 0,5 a 3 micras $^{(7)}$.

Qualquer que seja o processo a ser sub-
Os kits para aerossol são utilizados geralmente na terapêutica de afecções do trato respiratório para alívio de processos inflamatórios, congestivos e obstrutivos.
Na prática das instituições de saúde observa-se que 0 hipoclorito de sódio é o desinfetante de escolha para desinfecção de Kits para aerossol, devido principalmente ao seu baixo custo. 0 hipoclorito de sódio é indicado para desinfecção de artigos plásticos e borrachas, mas não deve ser utilizado em componentes metálicos devido a sua ação corrosiva. Acredita-se que a ação germicida seja por inibição de reações enzimáticas celulares, desnaturação protéica e inativação de ácido nucléico. Por ser um desinfetante de nível intermediário, tem ação sobre micobactérias, bactérias na forma vegetativa, vários vírus e fungos, porém não elimina esporos bacterianos ${ }^{(8)}$. 0 M inistério da Saúde ${ }^{(4)}$ recomenda para a desinfecção de artigos semicríticos o hipoclorito de sódio em concentrações de 10000 ppm (1\%) por 30 minutos ou 200 ppm (0,02\%) por 60 minutos. A concentração a $1 \%$ oferece a desvantagem do forte odor e requer enxágüe abundante para eliminar resíduos que poderiam desencadear irritações.

Muitos fatores afetam a estabilidade do cloro livre em solução de hipoclorito de sódio e sua atividade germicida. Estes fatores incluem a concentração de cloro, presença de íons e metais pesados, pH (mais ativo em pH ácido, porém menos estável), temperatura, luz, presença de bio-filme ou de matéria orgânica. Desta forma, 0 hipoclorito de sódio deve ser colocado em recipientes plásticos escuros com tampa, devido à sua fotossensibilidade e volatilidade. Compostos clorados são altamente instáveis, e por este motivo deve-se utilizámetido um determinado artigo (desinfecção/ esterilização), a primeira etapa, a qual garantirá a eficácia do processo, é a limpeza(8). A limpeza é o procedimento utilizado para a remoção de sujidade presente em qualquer superfície do artigo, por ação mecânica (fricção), química (soluções) ou térmica. Os métodos tradicionalmente utilizados neste fim incluem a limpeza manual e automatizada ${ }^{(6)}$.

0 uso de lavadoras termodesinfectadoras para a limpeza/desinfecção de artigos minimiza o risco de acidentes dos trabalhadores com o material biológico, por reduzir o manuseio dos artigos contaminados $s^{(4,6)}$. Entretanto, em nossa realidade, a maior parte dos estabelecimentos de saúde não dispõe destes equipamentos devido ao alto custo, restando a opção pela limpeza manual. Recomenda-se a utilização de detergentes enzimáticos como coadjuvante na limpeza manual ou automatizada dos artigos, principalmente os de configuração complexa, como as extensões dos kits para aerossol(6,8).

Outro aspecto importante a considerar, precedendo a desinfecção, é secagem do artigo, pois a presença de água no artigo dilui a solução química. Vale ressaltar, ainda, los no intervalo máximo de 24 horas após diluição ${ }^{(8-9)}$.

Para o enxágüe de artigos semicríticos submetidos à desinfecção de nível intermediário, não há necessidade de se utilizar água esterilizada, porém deve-se atentar para as condições mínimas de controle da água potável dispondo de um sistema de filtragem da água ${ }^{(6)}$.

A etapa seguinte, secagem, pode ser realizada com compressa ou pano limpo destinado exclusivamente a esta finalidade. Deve-se atentar para a secagem rigorosa, pois fungos e algumas bactérias vegetativas proliferam rapidamente em ambientes abafados e úmidos ${ }^{(3)}$.

0 armazenamento de artigos reprocessados por agentes químicos é a etapa de maior discussão e dificuldades. Embora o M inistério da Saúde ${ }^{(4)}$ preconize o uso imediato dos artigos termossensíveis expostos à esterilização por agentes químicos, proibindo o seu armazenamento, acredita-se, por esse mesmo princípio, que os artigos desinfetados em hipoclorito de sódio (desinfetante químico instável) também devam ser utilizados logo após o seu reprocessamento. 
O reprocessamento inadequado dos artigos pode acarretar sérios danos aos pacientes e profissionais. Para os pacientes os artigos podem tornar-se fonte de contaminação e aumentar o risco de desenvolver infecção(9-10). Para os profissionais, a freqüente exposição e manuseio de produtos químicos associados à negligência no uso de EPI potencializam os riscos ocupacionais. Desta forma, 0 profissional deverá buscar constantemente a qualidade e o aprimoramento do seu trabalho, evitando atitudes inadequadas e rotineiras(6). Na nova organização hospitalar a responsabilidade pelo controle de infecção deve ser de toda a equipe e não mais de uma Comissão de Controle de Infecção Hospitalar $(\mathrm{CClH})^{(11)}$.

A realização de atividades acadêmicas em uma unidade pediátrica suscitou discussões acerca do reprocessamento dos kits para aerossol, por questões referentes à descentralização do processo, a informalidade como o processo parecia acontecer, não havendo, por exemplo, um profissional escalado para a sua realização e a concomitância desta com o atendimento ao paciente.

Considerando que o reprocessamento de artigos é indiscutivelmente uma conduta essencial para o controle de infecção, atenta-se para a necessidade de estabelecer medidas de controle de qualidade visando melhoria na assistência ofertada. Desta forma, os objetivos deste estudo foram verificar uma possível contaminação microbiana em kits para aerossol após o reprocessamento e identificar os microrganismos presentes nestes itens que podem estar relacionados à infecção hospitalar nesta unidade.

\section{MÉTODO}

Trata-se de um estudo transversal e experimental, não comparativo e não randomizado realizado na unidade pediátrica de um hospital de grande porte público e de ensino, na cidade de Goiânia, Goiás, Brasil, no período de 01 a 30 de outubro de 2003, após aceite da unidade em questão e aprovação pelo Comitê de Ética do hospital (Protocolo CEPM HA/HC/UFG 074/2003).

0 reprocessamento dos kits para aerossol era realizado nesta unidade pediátrica, de forma descentralizada. Não foi objetivo deste estudo avaliar as etapas operacionais do reprocessamento destes artigos, mas avaliar por meio de análise microbiológica, as condições que estes artigos eram disponibilizados para uso na unidade pediátrica.

Foram analisados 15 kits para aerossol, previamente desinfetados em hipoclorito de sódio a 1\%, armazenados em um recipiente plástico com tampa e disponíveis à utilização. Por ser um serviço descentralizado, o reprocessamento dos kits era realizado por vários trabalhadores e a disposição dos artigos dentro do recipiente plástico ocorria de acordo com a demanda do uso e reprocessamento. Os kits não possuíam invólucros individuais e registros de período de utilização.
Para a realização da coleta de dados, procedeu-se por meio de técnica asséptica. 0 pesquisador fazia uso de gorro, máscara, sapato fechado, capote e luvas cirúrgicas estéreis e era auxiliado por um estudante de enfermagem paramentado e devidamente orientado e esclarecido acerca do estudo. A coleta foi realizada em uma sala restrita da unidade pediátrica sobre uma mesa submetida à limpeza e desinfecção e coberta com campos esterilizados.

Padronizou-se a coleta aleatória de 5 kits em um único dia da semana, perfazendo um total de 3 semanas. As amostras foram coletadas de três diferentes segmentos dos kits, sendo: máscara, copo e interior da extensão. Nas duas primeiras partes, utilizou-se um swab umedecido em solução salina esterilizada e no interior da extensão de plástico injetou-se esta mesma solução, que foi recoIhida em tubo de ensaio após contato com toda a superfície interna da extensão.

Após a coleta das amostras, os swabs foram inoculados em caldo tioglicolato suplementado com $0,8 \%$ ágar e incubados a $37^{\circ} \mathrm{C}$ por um período de 24 a 48 horas. A solução salina que imergiu os swabs e as amostras obtidas no interior da extensão foram semeadas pela técnica de gota ( $50 \mu \mathrm{L}$ ) em placas de ágar manitol, ágar M acConkey, ágar Sabouraud e ágar chocolate, incubadas a $37^{\circ} \mathrm{C}$ por 24 a 48 horas. As colônias desenvolvidas foram contadas, caracterizadas macroscópica e microscopicamente (coloração de Gram) e posteriormente foram realizados testes bioquímicos para identificação microbiana ${ }^{(12)}$. Os microrganismos isolados foram armazenados em frascos contendo ágar nutriente à temperatura de $-20^{\circ} \mathrm{C}$.

Os dados foram codificados e processados em quadros demonstrativos no Microsoft Office Word 2003.

\section{RESULTADOS E DISCUSSÃO}

O reprocessamento de kits para aerossol da unidade pediátrica era realizado de forma descentralizada e de acordo com o M inistério da Saúde ${ }^{(1)}$ a descentralização do reprocessamento de artigos não é recomendada, visto que aumenta consideravelmente as possibilidades de contaminação e compromete a qualidade do reprocessamento.

Neste estudo, do total de 15 kits para aerossol analisados, obteve-se uma amostragem de 15 copos, 15 extensões e 15 máscaras. Os segmentos contaminados são apresentados na Tabela 1, sendo $13(86,7 \%)$ copos, 13 $(86,7 \%)$ máscaras e $9(60,0 \%)$ extensões. Estes dados revelaram que apenas 10 unidades dos kits não apresentaram contaminação, destes, $2(13,3 \%)$ copos, 2 (13,3\%) máscaras e $6(40,0 \%)$ extensões.

Em semelhante estudo, os autores referem que das 232 máscaras para aerossóis pesquisadas, 33 estavam contaminadas, sendo 29 processadas pelo sistema descentralizado e 4 pelo sistema centralizado(13). 
Tabela 1 - Número e percentual de copos, extensões e máscaras contaminadas e microrganismos isolados - Goiânia - 2004

\begin{tabular}{lcccccc}
\hline \multirow{2}{*}{ Kits para aerossol $(\mathrm{n}=15)$} & \multicolumn{2}{c}{ Copo } & \multicolumn{2}{c}{ Extensão } & \multicolumn{2}{c}{ Máscara } \\
\cline { 2 - 7 } & $\mathbf{N}^{\mathbf{0}}$ & $\mathbf{\%}$ & $\mathbf{N}^{\mathbf{0}}$ & $\mathbf{\%}$ & \multicolumn{1}{c}{$\mathbf{N}^{\mathbf{0}}$} & $\mathbf{\%}$ \\
\hline Número de unidades contaminadas & 13 & 86,7 & 9 & 60,0 & 13 & 86,7 \\
Número UFC * isoladas & 39 & 38,6 & 20 & 19,8 & 42 & 41,6 \\
\hline
\end{tabular}

*Unidade Formadora de colônias

Foram isoladas 101 colônias de microrganismos dos 15 kits para aerossol, $39(38,6 \%)$ isoladas dos copos, 20 $(19,8 \%)$ das extensões e $42(41,6 \%)$ das máscaras (Qua- dro 1). A caracterização bioquímica dos microrganismos encontrados nos diferentes segmentos dos kits para aerossol são apresentados no Quadro 1.

Quadro 1 - Distribuição das amostras de kits para aerossol segundo a caracterização bioquímica dos microrganismos isolados - Goiânia - 2004

\begin{tabular}{|c|c|c|c|}
\hline - & & Microrganismos isolados & \\
\hline & Copo & Máscara & Interior da extensão \\
\hline BGP: Baciłos Gram- & 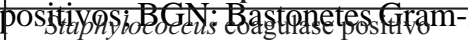 & negativpssngo filamentoso, BGP & Micrococcus $s p$ e leveduras \\
\hline 2 & Staphylococcus coagulase positivo & Staphylococcus coagulase positivo & Micrococcus sp e leveduras \\
\hline 3 & - & $\begin{array}{l}\text { Staphylococcus coagulase positivo, } \\
\text { Staphylococcus coagulase negativo }\end{array}$ & $\begin{array}{l}\text { fungo filamentoso, Staphylococcus } \\
\text { coagulase positivo }\end{array}$ \\
\hline 4 & Fungo filamentoso & Staphylococcus coagulase negativo & $\begin{array}{c}\text { Leveduras, BGP, Micrococcus sp, } \\
\text { fungo filamentoso }\end{array}$ \\
\hline 5 & BGP & BGP & Fungo filamentoso \\
\hline 6 & BGP & BGP & BGN não fermentadores e BGP \\
\hline 7 & BGP & BGP & - \\
\hline 8 & Leveduras & BGP & - \\
\hline 9 & BGP & - & Staphylococcus coagulase negativo \\
\hline 10 & Micrococcus sp & Micrococcus sp, BGP & 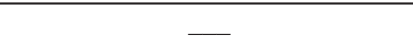 \\
\hline 11 & BGP & - & - \\
\hline 12 & $\begin{array}{l}\text { BGN não fermentadores, Leveduras e } \\
\text { Staphylococcus coagulase negativo }\end{array}$ & BGP & BGP \\
\hline 13 & $\begin{array}{l}\text { BGN fermentadores, BGN não } \\
\text { fermentadores, BGP e leveduras }\end{array}$ & BGP & BGP \\
\hline 14 & - & BGP & - \\
\hline 15 & BGP & BGP & 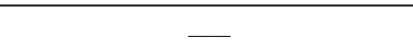 \\
\hline
\end{tabular}

BGP: Bacilos Gram-positivos; BGN: Bastonetes Gram-negativos

Dentre as bactérias isoladas e consideradas patogênicas neste estudo, destacaram-se os Staphylococcus coagulase positivo, Staphylococcus coagulase negativo, Bastonetes Gram negativo fermentadores, Bastonetes Gram negativo não fermentadores e M icrococcus sp; dentre os fungos destacaram-se as leveduras. A maioria destes microrganismos faz parte da microbiota autóctone humana, porém desequilíbrios existentes entre esta microbiota e os mecanismos de defesa do hospedeiro podem desencadear quadros de infecções hospitalares ${ }^{(14)}$.

Apesar das extensões apresentarem o menor número de amostras contaminadas, percebe-se a variedade de microrganismos potencialmente patogênicos isolados. Esta quantidade reduzida de microrganismos isolados das extensões, quando comparados aos isolados dos copos e máscaras, talvez se deva ao modo utilizado para fazer a coleta: nas extensões foi injetada solução salina esterilizada no lúmen destacando os microrganismos presentes na superfície; nos copos e máscaras fez-se friç̧ão com swabs embebidos em salina facilitando a remoção dos microrganismos.
Este fato pode ser explicado pela formação de biofilme no interior das extensões. Biofilme é um consórcio microbiano envolvido em uma matriz de polissacarídeos extracelulares resultante da aderência, multiplicação e desenvolvimento de microrganismos sobre superfícies sólidas. É geralmente formado em resposta às condições ambientais desfavoráveis, sendo o resultado de uma estratégia universal usada pelos microrganismos para otimizar a sobrevivência e perpetuação da espécie ${ }^{(15)}$.

A fricção é o método ideal para desagregação dos microrganismos que compõem o biofilme, e esta etapa não foi realizada no lúmen das extensões, o que pode explicar a reduzida quantidade de amostras isoladas deste segmento.

A configuração de artigos tubulares, como a extensão dos kits para aerossol, apresenta dificuldades no desempenho da limpeza, o que pode comprometer a eficácia da lavagem, secagem e desinfecção. Para a melhoria da qualidade deste processo, indica-se imersão dos artigos tubu- 
lares em solução de detergente enzimático e enxágüe abundante com água corrente através de torneiras com bico de pressão. A secagem rigorosa deve ser realizada com ar comprimido medicinal. A presença de água nos lumens destes artigos dilui o desinfetante e altera sua concentração(6). Todas as etapas do reprocessamento de artigos devem ser rigorosamente seguidas e embasadas em documentos que obedeçam à legislação vigente ${ }^{(4)}$. Não avaliamos neste estudo as etapas operacionais do reprocessamento dos kits para aerossol.

Em um estudo analisou-se a contaminação microbiológica de 65 broncoscópios após a desinfecção de alto nível com glutaraldeído a $2 \%{ }^{(16)}$. Após o reprocessamento foram encontrados nas amostras Staphylococcus epidermidis, Enterobacter sp, Acinetobacter baumanni, Streptococcus do grupo viridans, Staphylococcus aureus, Staphylococcus coagulase negativa, Streptococcus beta hemolíticos, e em cinco amostras houve a detecção de micobactérias. Concluíram que o reprocessamento dos broncoscópios não foi eficaz, acarretando em uma série de riscos ao cliente ${ }^{(16)}$. Tanto as extensões dos kits para aerossol como os broncoscópios são artigos tubulares e considerados semicríticos, porém devido a maior invasibilidade, os broncoscópios devem ser submetidos à desinfecção de alto nível.

Os microrganismos isolados das máscaras foram, na maioria, Bacilos Gram-positivos, que podem ser provenientes do meio ambiente. Porém, as bactérias potencialmente patogênicas encontradas neste estudo, como Staphylococcus coagulase positivo, Staphylococcus coagulase negativo e Micrococcus sp, podem ser encontrados na microbiota normal da pele ${ }^{(17)}$. Aproximadamente $20 \%$ das pessoas são portadoras cutâneas de $\mathrm{S}$. aureus, mas este número pode ser superior nos profissionais de saúde ${ }^{(14)}$.

A microbiota transitória, adquirida pelo contato com pacientes e meio ambiente, tem alta patogenicidade sendo responsável pela maioria das contaminações cruzadas(18). A simples técnica de higienização das mãos, utilizando-se água e sabão, remove facilmente esta microbiota, porém estudos demonstram a pouca importância dada a esta prática e evidenciam a necessidade de um programa educativo sistemático sobre 0 assunto(19-20).

A detecção microbiana nos Kits para aerossol indica que provavelmente ocorreram falhas no reprocessamento

\section{REFERÊNCIAS}

1. Brasil. Ministério da Saúde. Manual de reprocessamento de artigos e superfícies em estabelecimentos de saúde. Brasília; 1994.

2. Cunha $A F, M$ iranda $A M F$, Rodrigues $C T$, Lech J, Graziano KUG, Sousa LP, et al. Recomendações práticas para processos de esterilização em estabelecimentos de saúde. Campinas: Komedi; 2000. de artigos e/ ou contaminação após o processo. Porém, não foi o objetivo deste estudo analisar as etapas do reprocessamento, para verificar em que etapa as possíveis falhas ocorreram. Todos os microrganismos isolados, na sua forma vegetativa, são inativados quando expostos ao procedimento de desinfecção por hipoclorito de sódio a $1 \%$ no período de 30 minutos se forem obedecidas todas as recomendações normatizadas (concentração, pH, temperatura, tempo, entre outros) ${ }^{(5)}$. É consenso na literatura que o controle de qualidade do reprocessamento de artigos somente é obtido a partir do monitoramento de todas as suas etapas ${ }^{(4)}$. E o que se espera de um artigo pós-reprocessamento, pronto para o uso, é a segurança garantida pelo processo ao qual foi submetido. Assim, a presença destes microrganismos contraria este processo ao qual foi exposto.

Estes resultados reforçam a necessidade da conscientização dos profissionais sobre os procedimentos de desinfecção e da importância da técnica de higienização das mãos. Partindo da compreensão de que o controle de infecção baseia-se na constante busca de qualidade e aprimoramento do trabalho, percebe-se que atitudes errôneas e rotineiras podem gerar ou causar risco à saúde do trabalhador ou do cliente durante a sua assistência.

\section{CONCLUSÃO}

Este estudo permitiu concluir que houve desenvolvimento de microrganismos virulentos isolados dos kits para aerossol reprocessados na unidade pediátrica de um hospital público e de ensino. Estes fatos indicam que provavelmente ocorreram falhas no reprocessamento de artigos e/ ou contaminação após o processo, visto que o método utilizado para o reprocessamento na unidade (hipoclorito de sódio a 1\%) tem ação biocida comprovada para os microrganismos isolados neste estudo, quando são seguidas todas as condições recomendadas.

Há necessidade de se identificar estas falhas, padronizar normas e rotinas para melhor operacionalização do reprocessamento de artigos, além de implantar a educação permanente dos profissionais, o que contribuirá para a diminuição de fatores de riscos de infecção e melhoria da qualidade assistencial ofertada. Um investimento a ser empreendido buscando a qualidade do serviço é a centralização do reprocessamento dos artigos.

3. Graziano KU, Silva A, Bianchi ERF. Limpeza, desinfecção, esterilização de artigos e anti-sepsia. In: Fernandes AT, Fernandes MAV, Ribeiro Filho N, editores. Infecção hospitalar e suas interfaces na área da saúde. São Paulo: Atheneu; 2000. p. 266- 305.

4. Brasil. Ministério da Saúde. Orientações gerais para Central de Esterilização. Brasília; 2001. 
5. Rutala WA, Weber JD. Draft Guideline for Disinfection and Sterilization in Healthcare Facilities, 2002 [text on the Internet]. Atlanta: CDC; 2002 [cited 2005 May 2]. Available from: http://www.cdc.gov/ncidod/hip/dsguide. htm

6. Sociedade Brasileira de Enfermeiros de Centro Cirúrgico, Recuperação Anestésica e Centro de Material e Esterilização (SOBECC). Práticas Recomendadas - SOBECC. 4ạ ed. São Paulo; 2007.

7. Schmitz EMR. Inaloterapia: fundamentos para a atuação da enfermagem pediátrica. In: Schmitz EM R, organizadora. A enfermagem em pediatria e puericultura. São Paulo: Atheneu; 2000. p. 311-22.

8. Basso M, Giunta APN. Limpeza e desinfecção de artigos médicos-hospitalares. In: Associação Paulista de Estudos e Controle de Infecção Hospitalar (APECIH). Limpeza, desinfecção de artigos e áreas hospitalares e antisepsia. São Paulo; 2004. p. 1-17.

9. Müller S, Gruber AC, Hoefel HHK, Barros SGS. Manometria esofágica: limpeza e desinfecção do equipamento com glutaraldeído. Arq Gastroenterol. 2001;38(4):276-80.

10. Balthazar MB, Santos BM. A desinfecção de nebulizadores em uma unidade básica de saúde de Ribeirão Preto. Rev Esc Enferm USP. 1997;31(1):23-35.

11. Almeida JGO. Hospital remodelado e o controle de infecção. In: Fernandes AT, Fernandes MAV, Ribeiro Filho $\mathrm{N}$, editores. Infecção hospitalar e suas interfaces na área da saúde. São Paulo: Atheneu; 2000. p. 1700-5.

12. Koneman EW, Allen SD, Janda WM, Schreckenberger PC, Winn WC Jr. Diagnóstico microbiológico: texto e atlas colorido. São Paulo: Medsi; 2001.
13. Pereira LV, Alves JR, Oliveira AG, Pereira GA, Morais CA. Reprocessamento de máscaras para aerossóis: comparação entre sistemas centralizado e descentralizado. Nursing (São Paulo). 2002;5(51):15-9.

14. Fernandes AT, Ribeiro Filho N. Infecção hospitalar: desequilíbrio ecológico na interação do homem com sua microbiota. In: Fernandes AT, Fernandes MAV, Ribeiro Filho N, editores. Infecção hospitalar e suas interfaces na área da saúde. São Paulo: Atheneu; 2000. p. 163-214.

15. Costerton WJ, Wilson M. Introducing biofilms. Biofilms. 2004;1(1):1-4

16. Grande NS, Nakayama RA, Machado AMO, Yamaguti FA, Uehara C. Avaliação do risco de contaminação por bactérias, no paciente submetido à broncoscopia, após o reprocessamento do broncoscópio. J Pneumol. 2002;28 (5):250-60

17. Brooks JA, Butel JS, Ornston LN, editores. Jawetz, M elnicki \& Adelberg: microbiologia médica. Rio de Janeiro: Guanabara Koogan; 2000.

18. Yamaushi NI, Munhóz CHF, Ferreira AM GB. Procedimentos invasivos. In: Fernandes AT, Fernandes MAV, Ribeiro Filho N, editores. Infecção hospitalar e suas interfaces na área da saúde. São Paulo: Atheneu; 2000. p. 957-97.

19. Carvalho LPF. Avaliação da microbiota prevalente nas mãos dos profissionais de saúde do CTI de um hospital Universitário. Rev Med Minas Gerais. 2003;13(1):2-4.

20. Pittet D. Hand hygiene: improved instandards and practice for hospital care. Curr Opin Infect Dis. 2003;16(4): 327-35. 